\title{
PLACAS ECOEFICIENTES: APROVEITAMENTO DE RESÍDUO DE EVA EM COMPÓSITOS USADOS PARA ISOLAMENTO ACÚSTICO
}

\section{ECO-EFFIIIENT PLATES: UTILIZATION OFEVA RESIDUES IN COMPOSITES FOR ACOUSTIC INSULATION}

Heloisa R. T. Silva, Dra. (UNISUL);

Bruna Maylla M. Cavalcant (UNISUL);

Diego Valdevino Marques (UNISUL);

Paola Egert, Dra. (UNISUL);

Rachel Faverzani Magnago, Dra. (UNISUL);

Deise Rebelo Consoni, Dra. (UNISUL); Jasper José Zanco, Dr. (UNISUL)

\section{Palavras Chave}

EVA; Reaproveitamento; Isolamento Acústico

\section{Key Words}

EVA; Reuse; Insulation

\section{RESUMO}

O etileno acetato de vinila (EVA) é um polímero utilizado na confecção de materiais escolares, esportivos e no setor calçadista. Este gera resíduos, logo é necessário a sua reutilização. Visando isso, o trabalho tem como objetivo estudar placas produzidas a partir de EVA/cimento como isolante acústico e desta forma dar um destino a este material. Neste sentido a melhor mistura EVA/cimento foi estudada. Com a placa produzida foram investigadas suas características, para isto foram realizados os ensaios de absorção de água, acústica, e inflamabilidade e análise microscópica. Os resultados mostraram que a placa apresenta uma redução acústica mais eficiente nas frequências entre 800 e $1000 \mathrm{~Hz}$ quando comparada a uma parede de concreto. Desta forma o material mostra-se viável para o isolamento acústico possibilitando assim um novo destino produtivo para o resíduo de EVA.

\section{ABSTRACT}

Ethylene vinyl acetate (EVA) is a polymer used in the manufacture of school supplies, sports and footwear. The production process generates substantial amounts of residues, which should be reused. The aim of this study was to examine if plates produced from a mixture of EVA and cement can be used for acoustic insulation, thus giving a proper destination to the residues. For that purpose, the best mixture of EVA and cement was examined. The characteristics of the manufactured plates were analyzed, and water absorption, acoustic, flammability, and microscopic tests were carried out. The results showed that the acoustic reduction of the plates was more efficient in the frequencies between 800 and $1000 \mathrm{~Hz}$ as compared to concrete walls. This finding allows to conclude that EVA plates can be used for acoustic insulation, thus giving a proper destination to the residues. 


\section{INTRODUÇÃO}

O etileno acetato de vinila (EVA) é um polímero utilizado em indústrias calçadistas, em materiais escolares, em materiais esportivos, dentre outros. É um polímero termofixo, o que significa que ele é de difícil reprocessamento (POLARI FILHO, 2005). A decomposição de seus resíduos é lenta podendo levar entre 250 a 400 anos.

Seus resíduos representam de 2 a $3 \%$ da produção, e como o EVA é uma espécie de borracha expandida leve, gera um material remanescente que ocupa grande volume e acaba necessitando de muito espaço em seu armazenamento e para sua disposição final, sobrecarregando desta forma os aterros. Logo, o descarte destes resíduos constitui um sério problema ambiental.

Devido aos problemas ambientais recorrentes e a busca pelo desenvolvimento sustentável é necessário criar formas para gerenciar este descarte da forma adequada ou mesmo reaproveitá-lo em outros processos produtivos. Assim, para atender ao desejo de projetar materiais duráveis que cumpram a iminente demanda dos conceitos de construção sustentável, faz-se necessário a aplicação de novos materiais e métodos de produção. Atualmente, diversos estudos têm sido realizados com o intuito de introduzir resíduos de outros processos produtivos na construção civil. O que se tem observado é que a construção civil pode absorver esses materiais remanescentes e convertê-los em matéria prima. O setor já é, atualmente, um grande reciclador de resíduos de outras indústrias (DEMIREL, 2013; MALAIŠKIENĖ et al, 2011; MARQUES et al, 2016). Neste sentido, encontram-se na literatura pesquisas que constataram que o EVA na forma de aparas pode ser utilizado como agregado leve na construção civil (BEZERRA, 2002; UCHÔA et al, 2015; SILVA et al, 2014; ANDRADE e MEDEIROS, 2012).

Assim, o trabalho apresenta os resultados obtidos com a incorporação de EVA, na forma de aparas, em uma pasta de cimento e no formato de placas, no estudo sobre seu comportamento frente ao isolamento acústico. Além disso, foi realizado a caracterização microestrutural da placa, a absorção de água, e a inflamabilidade da mesma. Por fim, verificou-se a eficiência do isolamento acústico das placas em decorrência do revestimento externo empregado na mesma, comparado com uma caixa de concreto convencional e uma caixa de gesso acartonado.

\section{METODOLOGIA}

\subsection{Resíduo}

O resíduo de EVA, proveniente da indústria calçadista, foi recebido na forma de aparas em tamanhos variando entre 1 a $2 \mathrm{~cm}$ conforme pode ser visualizado na Figura 1.

Figura 1 - Resíduo de EVA.

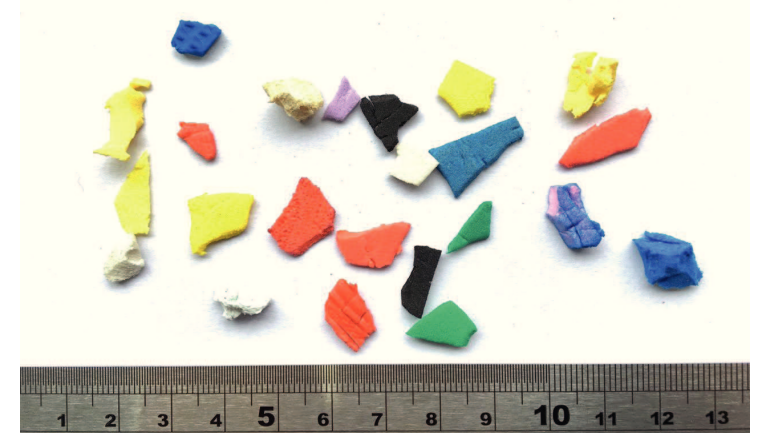

Fonte: Autores

O resíduo foi misturado a uma pasta de cimento com o objetivo de gerar uma placa do tamanho $20 \mathrm{~cm} \times 40 \mathrm{~cm} \times$ $2,0 \mathrm{~cm}$. Através desta placa piloto observou-se as características deste novo material, com vistas a uma aplicação ecoeficiente, onde o conforto habitacional poderá estar aliado ao reaproveitamento de um resíduo do setor produtivo.

\subsection{Preparação dos Corpos de prova}

$O$ procedimento dessa etapa constituiu-se em realizar a montagem de corpos de prova prismático $20 \mathrm{~cm} x$ $40 \mathrm{~cm} \times 2,0 \mathrm{~cm}$ para escolher a melhor proporção entre os materiais cimento CP-V, EVA em forma de aparas e água. A escolha dos traços de estudo se baseou no trabalho de SOUZA JUNIOR (2013), onde foram executados as seguintes proporções de materiais 1:0,62:0,35; 1:0,62:0,45 e 1:0,62:0,55 (cimento:EVA:água). O procedimento da montagem de corpo de prova consistiu na colocação da mistura já homogeneizada dos materiais no molde (Figura 2).

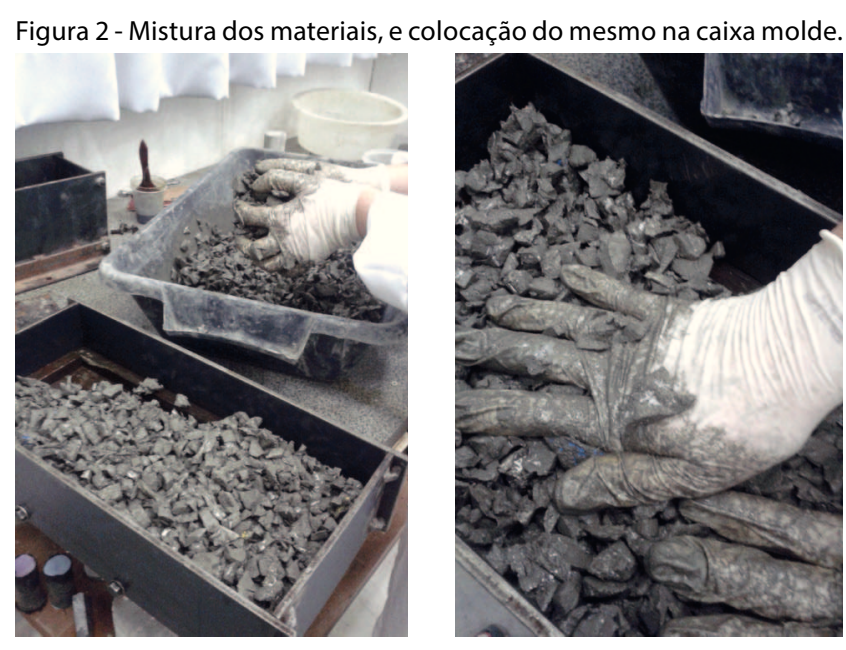

Fonte: Autores 
Após a acomodação da mistura, o molde foi levado a uma prensa hidráulica onde foi aplicada uma carga de cinco toneladas sobre o material, sustentada por vinte e quatro horas. O molde foi retirado da prensa e a placa foi desformada, conforme Figura 3.

Figura 3 - Aplicação de 5 toneladas e placa pronta após 24 horas.
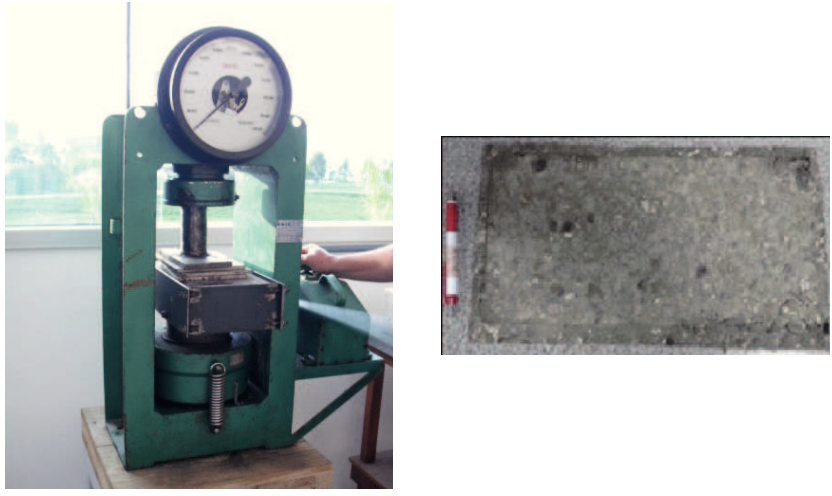

A escolha do melhor traço foi feita visualmente, através da comparação dos corpos de prova e pela trabalhabilidade na execução do mesmo, durante o procedimento de montagem do corpo de prova. Também foi testado um revestimento com papel kraft e outro com gesso para melhorar o acabamento final do material.

\subsection{Microscopia Eletrônica de Varredura e Análise} de Imagem por Microscopia Estereoscópica

Fotomicrografias das placas EVA/cimento foram realizadas por microscopia eletrônica de varredura em um equipamento JEOL modelo JSM 6060, operando a uma voltagem de $10 \mathrm{kV}$. A porosidade da placa foi analisada e tratada estatisticamente através do software ImageJ Version 1,51h. A coleta das amostras para análise por microscopia estereoscópica Binocular (Stemi DV4, Zeiss) foi feita à $14 \%$ de umidade, com o medidor de umidade (Marca Moisture Meter MD-2G) inserido a 8,5 mm na amostra.

\subsection{Absorção em água}

O procedimento seguiu o método gravimétrico preconizado pelo Standard Test Method for Water Absorption of Plastics D 570-98. O resultado apresentado é aquele obtido pela média da repetição de três corpos de prova. Inicialmente a amostra foi seca em estufa a $50^{\circ} \mathrm{C}$ durante 24 horas. A pesagem do material seco foi realizada em uma balança digital com precisão de 0,01g da marca Shimadzu (modelo BL $3200 \mathrm{H}$ ). Em seguida, a amostra foi imersa num banho de água destilada a uma temperatura de $25^{\circ} \mathrm{C}$. A amostra foi deixada nesta condição durante 24 horas, após este período foi retirada da imersão, seca com toalhas de papel e pesada novamente. $O$ índice de absorção de água é, então, obtido segundo a expressão

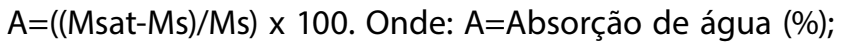
Msat - Massa da amostra saturada (g); Ms - Massa da amostra seca $(\mathrm{g})$

\subsection{Inflamabilidade}

Para o ensaio de queima foram usadas amostras no tamanho de $0,3 \mathrm{~cm} \times 13 \mathrm{~cm} \times 1 \mathrm{~cm}$ com o melhor traço estudado. $O$ ensaio seguiu a norma UL 94 (teste queima vertical e horizontal). A norma brasileira sobre inflamabilidade é baseada nesta norma internacional, mas é voltada para o PU, logo optou-se por utilizar a norma internacional.

\subsection{Avaliação de isolamento acústico}

Para a realização do ensaio de isolamento acústico foi feita a montagem de uma caixa produzida com placas EVA/cimento, para verificar o comportamento de redução sonora. As placas de EVA/cimento, EVA/cimento/papelkraft e de EVA/cimento/gesso foram produzidas com encaixe macho e fêmea para a montagem das caixas que foram utilizadas no mesmo ensaio (Figura 4).

As normas relacionadas a isolamento acústico que merecem destaque abordam o conforto acústico em áreas habitadas. São elas a NBR10151/2000 (Acústica - Avaliação do ruído em áreas habitadas, visando o conforto da comunidade - Procedimento) e NBR 15575/2013 (Edificações habitacionais - Desempenho). Entretanto, nenhuma delas descreve um procedimento experimental para verificação de eficiência do material. Portanto, adotou-se os experimentos desenvolvidos por ANDRADE et al (2012) e SOUZA JUNIOR(2013).

Além disso, foi feita a montagem de uma caixa de concreto convencional e uma outra de gesso acartonado, afim de comparar o comportamento destas com as caixas de EVA.

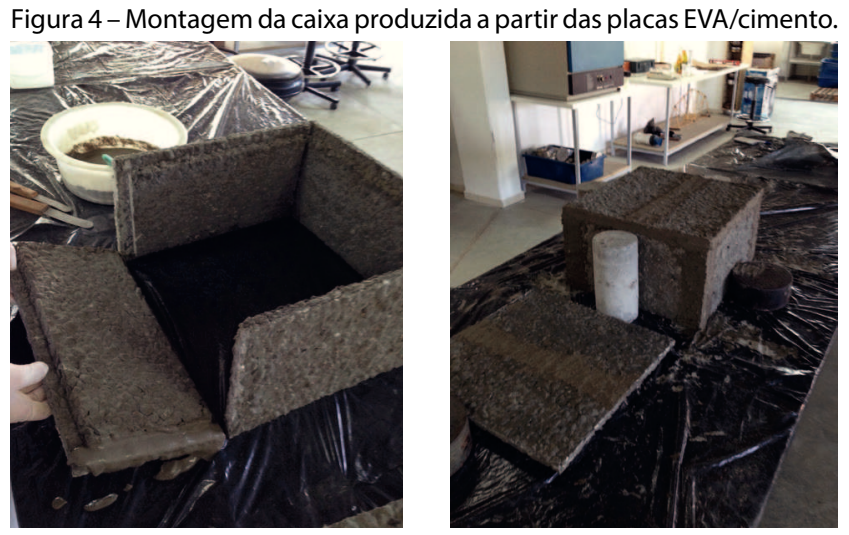




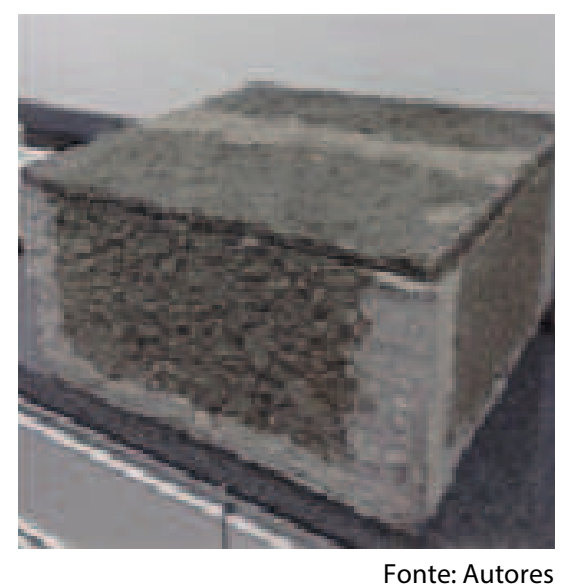

Para a montagem da caixa de gesso acartonado, foi utilizado um material comercial. A mesma foi cortada mantendo as dimensões do material desenvolvido. Para a junção entre as placas foi utilizado cola de gesso e fita crepe.

Com todas as caixas finalizadas, deu-se início aos ensaios de avaliações de isolamento acústicos. Este consiste em realizar a medição do nível de intensidade sonoro detectado por um decibilímetro (Instrutherm - Modelo DEC 300), a partir de uma fonte sonora (mp3) emitindo em uma sala enclausurada, buscando evitar a interferência sonora externa. A medição foi feita em quatro pontos com distância equivalente de 0,71 m medidos a partir do centro da emissão da fonte sonora e afastamento de 1,0 $\mathrm{m}$ das paredes da sala (ABNT NBR 10151/2003). Em cada ponto foram realizadas seis medições, utilizado-se tons puros nas frequências de 125 Hz, 250 Hz, 500 Hz, 1000 Hz e 2000 Hz.

Para verificar a eficiência na redução sonora foi realizado uma medição do som ambiente da sala que era de 27,9 $\mathrm{dB}$ e do som sem nenhuma barreira de todas as frequências, definindo-se assim o som ambiente. Posteriormente a fonte sonora foi colocada dentro de cada caixa (concreto, EVA/cimento, EVA/cimento/papelkraft, EVA/cimento/ gesso e gesso acartonado) para se realizar as medições a partir da emissão sonora nas diferentes frequências. Além disso, foi realizado o ensaio colocando as caixas de EVA dentro da caixa de concreto, afim de simular o seu uso e conferir a sua eficiência como isolamento acústico quando a mesma for incorporada em parede de concreto. Este esquema está ilustrado na figura 5.
Figura 5 - Sistema caixa EVA/cimento dentro da caixa de concreto com som MP3 dentro.
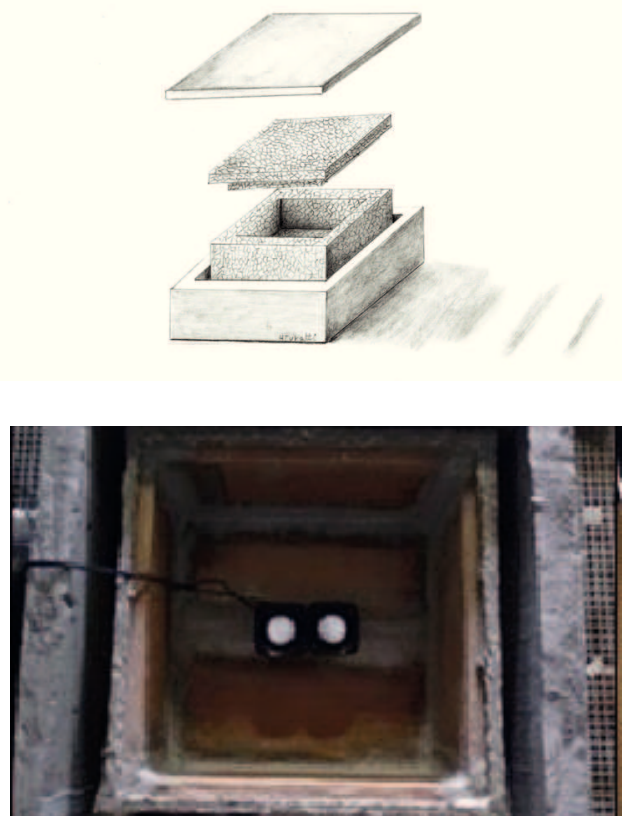

Fonte: Autores

\section{RESULTADOS}

\subsection{Apresentação dos Corpos de prova}

O melhor traço obtido foi de 1:0,62:0,45 (cimento:EVA:água), pois proporcionou a melhor cobertura das aparas de EVA pelo cimento e com a melhor trabalhabilidade dos traços. Referente ao acabamento do material, usou-se papel kraft (Figura 6a) e gesso (Figura 6b) durante a moldagem nos dois lados da placa para melhorar o revestimento do produto final.

Figura 6 - Placa de EVA/cimento acabada com (a) papel kraft e (b) gesso.

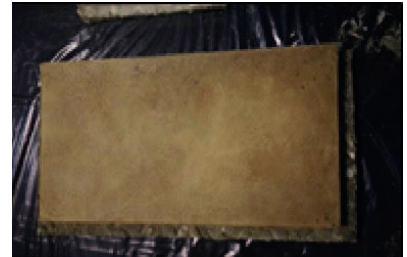

(a)

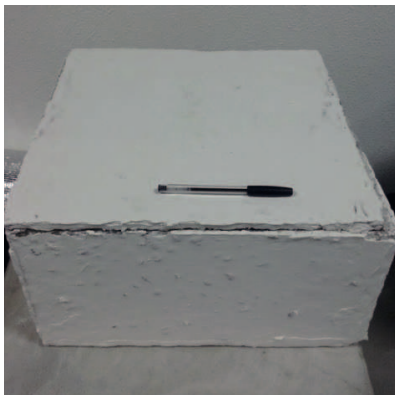

(b)
Fonte: Autores

\subsection{Microscopia Eletrônica de Varredura e Análise de Imagem por Microscopia Estereoscópica}

Na Figura 7 é apresentada a fotomicrografia realizada sobre a placa EVA/cimento em uma região de fronteira entre uma partícula de EVA e da fase cimentícia. 
Figura 7 - Micrografia da Placa de EVA/cimento.
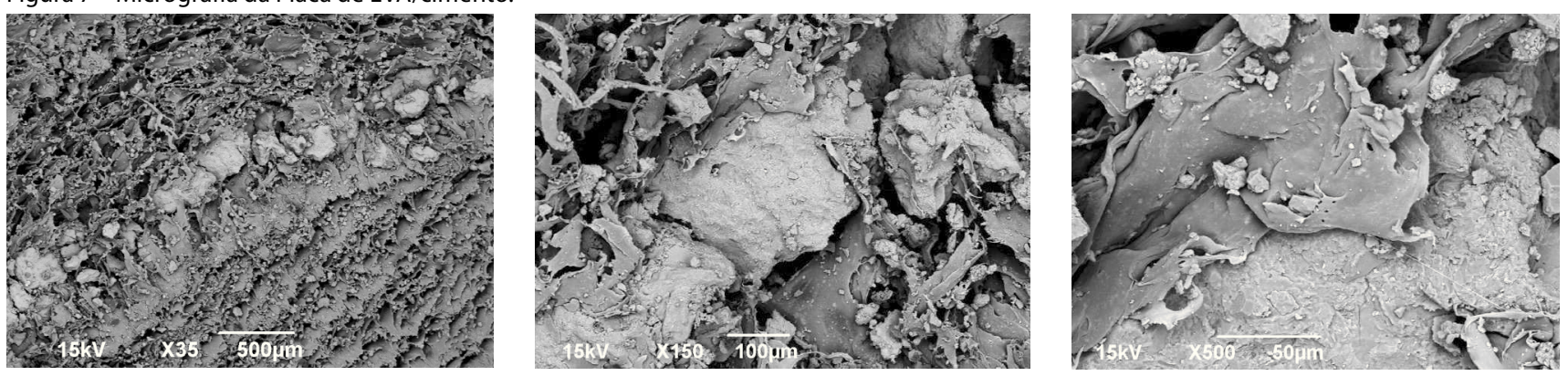

Fonte: Autores

Como pode-se notar ocorre a coesão entre as fases sendo difícil a identificação da fronteira. A adesão das fases pode ser atribuída principalmente a pressão aplicada na preparação das placas, tendo em vista que a interfase EVA e cimento promove interações intermoleculares fracas do tipo van der Waals e dipolo-dipolo, deste modo o cimento deve realizar o encapsulamento do EVA.

A Figura 8 apresenta os cortes transversais da placa EVA/cimento com aumento de 400x, evidenciando a porosidade das diferentes partículas de EVA presente no corte.

A análise da imagem evidencia que existe diferença

Figura 8. Imagens dos cortes transversais de uma placa EVA/cimento evidenciando o EVA (a) branco, (b) azul e (c) preto, com as respectivas imagens tratadas dos cortes transversais abaixo de cada corte original.
Fonte: Autores

significativa entre os tipos de EVA, encontrados no resíduo, em relação ao número e tamanho de partículas. Os diâmetros dos poros pode ser visualizado no histograma de frequência apresentado na Figura 9.

Figura 9. Histograma de frequência do EVA Azul, Branco e Preto.
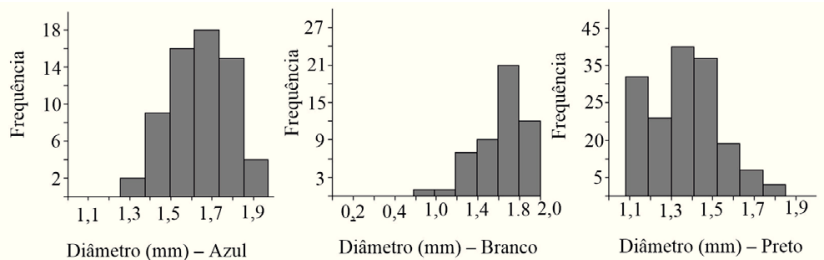

Fonte: Autores
Os histogramas (Figura 9) mostram que para o material de cor azul o tamanho médio dos poros está entre 1,3 e 1,9 mm, já o material branco apresenta uma distribuição entre 1,0 e 2,0 mm e o material de cor preta entre 1,1 e 1,8 $\mathrm{mm}$. Existe uma diferença significativa entre o diâmetro médio de poros do material de cor preta quando comparado com os demais.

\subsection{Absorção em água}

O valor de absorção de água de $20 \%$ foi encontrado a partir da média de três medidas realizadas. A absorção de água ocorre devido aos microporos existentes no material como foi visualizado na micrografia (Figura 8). A adesão entre cimento e EVA foi suficiente para não permitir que o material se deformasse com a absorção de água, não exibindo rachaduras ou quebra da placa. Também foi constatado que após $24 \mathrm{~h}$ o material perdeu completamente a água, deste modo não sendo evidenciada adsorção de água ao material, devido as possíveis ligações intermoleculares entre a água e parte polar (-CO2-) do EVA, bem como ao cimento.

\subsection{Inflamabilidade}

Os materiais desenvolvidos foram investigados quanto a capacidade de propagar chama na direção vertical e horizontal, pois esses apresentam a possibilidade de uso como isolante acústico nestas posições, por exemplo, paredes e teto/piso.

A Figura 10 ilustra o resultado da queima vertical. Os testes de queima mostraram que não houve a extinção da chama, a combustão foi auto sustentável levando a queima completa dos corpos de prova de EVA/cimento (Figura 10a). No ensaio, os corpos de prova se consumiram por inteiro, consequentemente, não se encaixando em nenhuma classificação da norma. O material queimou totalmente num tempo médio de 2,59s. Considerando que a peça tem $135 \mathrm{~mm}$, pode-se dizer que a velocidade de queima foi de $52,12 \mathrm{~mm} / \mathrm{s}(0,05 \mathrm{~m} / \mathrm{s})$. Logo percebe-se que 
a placa não apresenta característica anti-chama, mesmo com a presença de cimento. Na busca por melhores resultados, foram produzidos novos corpos de prova, tendo como diferencial a adição de Alumina tri-hidratada (ATH) usado como agente anti-chama e supressor de fumaça (Figura 10b). Foi então utilizado $40 \%$ da massa de cimento de ATH.

Figura 10 - Ensaio de queima vertical das amostras de EVA/ cimento (a) sem ATH e (b) com ATH.

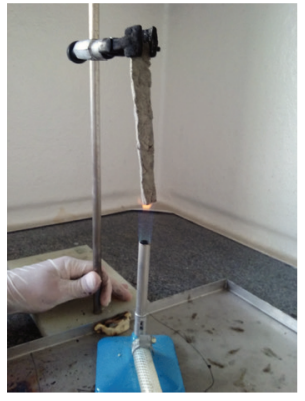

(a)

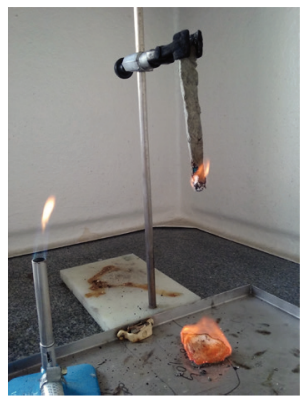

(b)

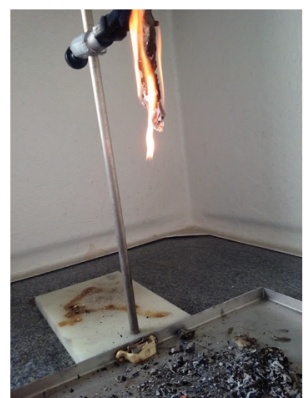

(c)

Fonte: Autores

Neste caso o ensaio mostrou que o ATH evitou a queima de todas as peças ensaiadas (Figura 10b). Um estudo mais detalhado pode ser realizado sobre o uso de anti-chama no material. Nesta condição o encapsulamento do EVA na placa mostrou-se eficiente, sendo que nenhum corpo de prova emitiu gotas ou fagulhas que incendeiam o algodão e a classificação da UL 94 foi de V0 (Quando a soma dos tempos de duração da chama não for superior a 50 segundos e, a camada de algodão não incendiar por gotejamento do material) para todos os corpos de prova.

A Figura 11 apresenta o ensaio de queima horizontal do material. Neste caso, após 30s de exposição a chama, o fogo se extinguiu sem propagação, ou seja, a combustão não atingiu a marca de $25 \mathrm{~mm}$ como indicado pela UL 94. As amostras apresentadas na Figura 11b são resultado do ensaio de queima horizontal.
Figura 11 - (a) Ensaio de queima horizontal das amostras de EVA/cimento em execução e (b) resultado final.

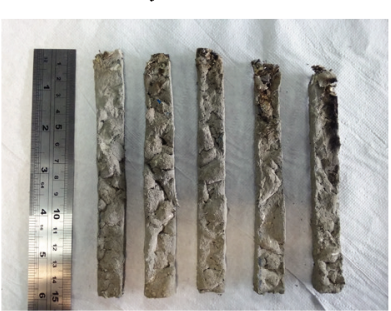

(a)

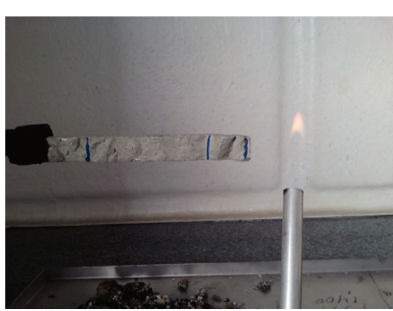

(a)
Fonte: Autores

Os resultados indicam que a placa apresenta resistência ao fogo quando este sofre exposição à chama horizontalmente. Indicando que a placa poderia ter utilização em chão ou teto numa habitação.

\subsection{Avaliação de isolamento acústico}

A Figura 12 apresenta os resultados de curvas de audibilidade das caixas de EVA/cimento, EVA/cimento/papeIkraft e EVA/cimento/gesso. Deste modo foi verificado o efeito do acabamento no tratamento acústico.

Figura 12 - Perfil de nível de intensidade Sonora das caixas EVA/cimento, EVA/cimento/papelkraft e EVA/cimento/gesso.

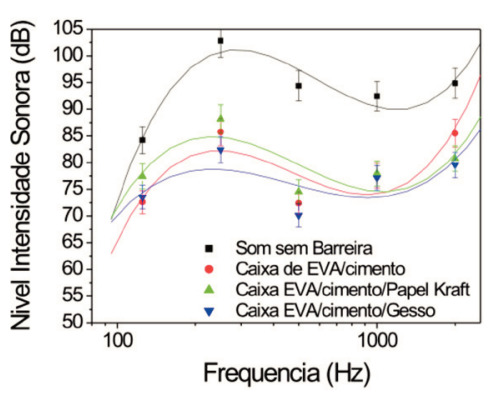

Pode-se observar que as três placas apresentaram uma redução em relação ao som emitindo pela fonte sonora. As placas produzidas reduzem o nível de intensidade em até $15 \mathrm{~dB}$ à $1000 \mathrm{~Hz}$. Pode-se comentar também que os diferentes acabamentos não interferem no resultado de proteção acústica. Indicando que a placa apresenta propriedades eficientes para este fim.

A Figura 13a apresenta as avaliações sobre isolamento acústico dos novos materiais quando posicionados dentro da caixa feita de concreto. A Figura 13b apresenta as avaliações em relação a caixa de gesso acartonado, já que o mesmo vem sendo cada vez mais utilizado no Brasil com a finalidade de proteção acústica. 
Figura 13 - Perfil de nível de intensidade Sonora das caixas EVA/cimento, EVA/cimento/papelkraft e EVA/cimento/gesso.

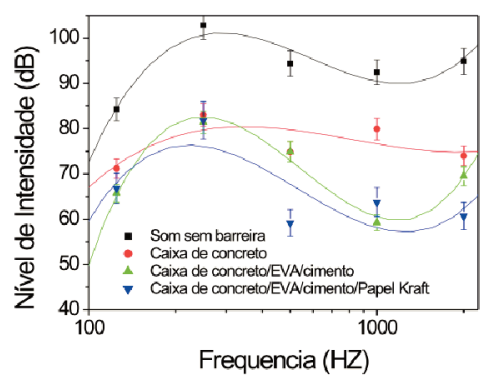

(a)

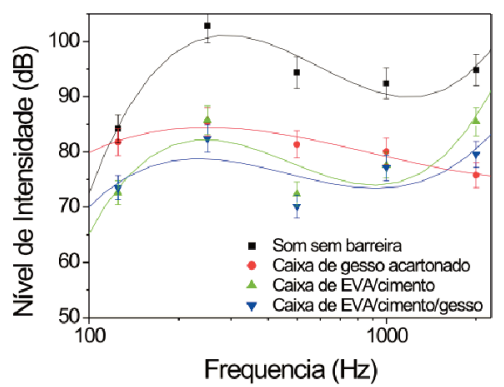

(b)

Fonte: Autores

Foi possivel constatar em todos os ensaios (Figura 13a e 13b) que todas as caixas montadas resultaram em uma redução dos níveis de intensidade sonora detectados, se comparada ao som detectado sem nenhuma barreira. Esta propriedade foi atribuída principalmente a estrutura de microporos do EVA que absorveu as ondas sonoras.

Em relação a simulação da utilização das placas de EVA em uma estrutura de concreto, como pôde ser visto na Figura 13a, para frequências mais baixa as placas apresentaram comportamento de isolamento acústico semelhante ao apresentado pela caixa de concreto. Mas em frequências mais elevadas observa-se um comportamento diferente. Para intensidades sonoras emitidas pela fonte a uma frequência superior a $200 \mathrm{~Hz}$, os níveis de intensidades detectados pelo equipamento são menores quando foi utilizado a caixa estudada dentro da caixa de concreto do que aquela obtida com apenas a caixa de concreto. Este comportamento no isolamento acústico em altas frequências é típico de materiais porosos e fibrosos. Na frequência de 500 $\mathrm{Hz}$ pode ser observado uma redução de até $35 \mathrm{~dB}$ no nível sonoro detectado a partir da caixa de EVA/cimento dentro da caixa concreto, em relação ao som emitido. Enquanto a caixa de concreto sozinho reduz 19,5 dB.

Na Figura 10b, para frequências entre 300 e $800 \mathrm{~Hz}$, as caixas de EVA/cimento apresentaram uma redução maior no nível de intensidade sonora detectado, do que na caixa de gesso acartonado. $\mathrm{Na}$ frequência de $500 \mathrm{~Hz}$ observa-se que a caixa de gesso apresentou uma redução de $13 \mathrm{~dB}$ no nível sonoro detectado, enquanto que a caixa de placas EVA/cimento apresenta valores reduzidos na ordem de $20 \mathrm{~dB}$. Para frequências fora da faixa mencionada, observa-se um comportamento semelhante no uso dos diferentes materiais.

Estes resultados indicam que o material desenvolvido com acabamento de papel kraft e gesso mostraram-se eficazes no comportamento como isolante acústico indicando que estes poderiam substituir a brita leve dentro de uma parede de concreto ou ainda uma parede de gesso acartonado. O material estudado ainda apresenta a vantagem do controle de espessura e de distribuição de partículas, garantindo resultados de isolamento acústico mais eficientes.

\section{CONCLUSÕES}

O ensaio de absorção de água mostrou uma valor de $40 \%$ para a placa, resultado coerente com um material que apresenta microporos, comprovado pelas análises microestruturais.

No ensaio de queima a placa mostra que quando utilizada em situações verticais precisa da adição de um anti-chama. Mas ela pode ser utilizada em situações horizontais, como chão e teto por exemplo.

Os resultados de acústica mostraram que as placas com e sem acabamento não interferem em algumas frequências e melhoram o desempenho em outras. Vale agora focar novos estudos na estrutura física da placa buscando um desempenho melhor em frequências baixas também.

\section{AGRADECIMENTOS}

Ao Conselho Nacional de Desenvolvimento cientifico e Tecnológico - CNPq pela concessão de bolsa de iniciação cientifica através do Programa Institucional de Bolsa de Iniciação em Desenvolvimento Tecnológico e Inovação - PIBITI/Cnpq.

\section{REFERÊNCIAS}

ANDRADE, L. A. S.; MEDEIROS, R., Reaproveitamento de rejeitos de E.V.A. para a produção de placas utilizáveis na construção civil, Revista Científica Indexada Linkania Master - ISSN: 2236-6660, 2012.

ASSOCIAÇÃO BRASILEIRA DE NORMAS TÉCNICAS ABNT NBR 10151: 2003 - avaliação do ruído em áreas habitadas, visando o conforto da comunidade.

ASTM D570; Standard Test Method for Water Absorption of Plastics; 2010. 
BEZERRA, A. J. V. Utilização do resíduo da indústria de calçados (EVA - Etileno Acetato de Vinila) como agregado leve na produção de blocos vazados de concreto para alvenaria sem função estrutural, Dissertação de Mestrado, UFPB/CCT, 2002.

DEMIREL, B. Optimization of the composite brick composed of expanded polystyrene and pumice blocks. Construction and Building Materials. v. 40, p. 306 -313, 2013.

FARIA, R.; Placa verde; Revista téchne; edição 123; juIho, 2007; disponível em http://techne.pini.com.br/engenharia-civil/123/artigo285381-1.aspx; acesso: 02/11/2016

MALAIŠKIENĖ, J. VAIČIENĖ, M; ŽURAUSKIENĖ R. Effectiveness of technogenic waste usage in products of building ceramics and expanded clay concrete. Construction and Building Materials, v. 25, n. 10, p. 3869-3877, 2011.

MARQUES, D. V.; SILVA, H. R. T.; ARAUJO, H.; EGER, P.; MAGNAGO, R. M. Propriedades De Isolamento Térmico, Acústico E De Resistência À Compressão De Placas De PU com a Incorporação de Resíduo de PET e ALUMINA, Mix Sustentável, v. 3, 2016.

POLARI FILHO, R.S. Contribuição ao processo de reciclagem dos resíduos da indústria de calçados na construção civil: Bloco EVA - Uma alternativa às alvenarias das construções; Dissertação de Mestrado do Curso em Engenharia Urbana, Universidade Federal de Paraíba, janeiro de 2005.

SILVA, R. M.; ALVIM, R. C.; DOMINGUEZ, D. S., Estudo da resistência mecânica de um compósito cimentício leve reforçado com fibras de piaçava, Revista do Instituto Federal de Educação, Ciência e Tecnologia da Bahia, 2014.

SOUZA JUNIOR, Z., Estudo Mecânico e Acústico de uma Pasta de Cimento que recebeu a incorporação de resíduos provenientes de fábricas de Etileno Acetato de Vinila (E.V.A.), Trabalho de conclusão de Curso. Engenharia Ambiental, Unisul, Palhoça, SC, 2013.

UCHÔA, S. B. B.; TONHOLO, J.; ARRUDA, T. H. S. V.; GOMES, P.C. C.; MORAES, K. A. M., Prospecção tecnológica: painéis de vedação utilizando concreto leve e materiais reciclados, Cad. Prospec., Salvador, 2015 